\title{
Monitoring Culicine Mosquitoes (Diptera: Culicidae) as a Vector of Flavivirus in Incheon Metropolitan City and Hwaseong-Si, Gyeonggi-Do, Korea, during 2019
}

\author{
Young Yil Bahk', Seo Hye Park', Myung-Deok Kim-Jeon ${ }^{3}$, Sung-Suck $\mathrm{Oh}^{3}$, Haneul Jung ${ }^{2}$, Hojong Jun ${ }^{2}$, \\ Kyung-Ae Kim ${ }^{3}$, Jong Myong Park ${ }^{3}$, Seong Kyu Ahn², Jinyoung Lee ${ }^{2}$, Eun-Jeong Choi ${ }^{3}$, Bag-Sou Moon ${ }^{3}$, \\ Young Woo Gong ${ }^{3}$, Mun Ju Kwon ${ }^{3}$, Tong-Soo Kim²,* \\ ${ }^{1}$ Department of Biotechnology, College of Biomedical and Health Science, Konkuk University, Chungju 27478, Korea; '2Department of Parasitology \\ and Tropical Medicine \& Global Resource Bank of Parasitic Protozoa Pathogens, Inha University School of Medicine, Incheon 22212, Korea; \\ ${ }^{3}$ Department of Infectious Diseases Diagnosis, Incheon Metropolitan City Institute of Public Health and Environment, Incheon 22320, Korea
}

\begin{abstract}
The flaviviruses are small single-stranded RNA viruses that are typically transmitted by mosquitoes or tick vectors and are etiological agents of acute zoonotic infections. The viruses are found around the world and account for significant cases of human diseases. We investigated population of culicine mosquitoes in central region of Korean Peninsula, Incheon Metropolitan City and Hwaseong-si. Aedes vexans nipponii was the most frequently collected mosquitoes (56.5\%), followed by Ochlerotatus dorsalis (23.6\%), Anopheles spp. (10.9\%), and Culex pipiens complex (5.9\%). In rural regions of Hwaseong, Aedes vexans nipponii was the highest population (62.9\%), followed by Ochlerotatus dorsalis (23.9\%) and Anopheles spp. (12.0\%). In another rural region of Incheon (habitat of migratory birds), Culex pipiens complex was the highest population (31.4\%), followed by Ochlerotatus dorsalis (30.5\%), and Aedes vexans vexans (27.5\%). Culex pipiens complex was the predominant species in the urban region (84.7\%). Culicine mosquitoes were identified at the species level, pooled up to 30 mosquitoes each, and tested for flaviviral RNA using the SYBR Green-based RT-PCR and confirmed by CDNA sequencing. Three of the assayed 2,683 pools (989 pools without Anopheles spp.) were positive for Culex flaviviruses, an insect-specific virus, from Culex pipiens pallens collected at the habitats for migratory birds in Incheon. The maximum likelihood estimation (the estimated number) for Culex pipiens pallens positive for Culex flavivirus was 25. Although viruses responsible for mosquito-borne diseases were not identified, we encourage intensified monitoring and long-term surveillance of both vector and viruses in the interest of global public health.
\end{abstract}

Key words: Mosquito, flavivirus, surveillance, insect-specific flavivirus, climate change

\section{INTRODUCTION}

Mosquito-borne diseases highlighted and gained increased focus [1-4] as the effects of climate change on public health worldwide have been recognized. Changes in the prevalence of mosquito-borne diseases have attracted attention. In fact, most land regions are experiencing greater warming than the global average [5]. Climate change is expected to accelerate in the future and the outcome for the Korean Peninsula is expected to be relatively large (e.g., temperature rise, rainfall change, etc.) [6]. According to a report by the Korea Meteorological

\footnotetext{
- Received 29 June 2020, revised 7 September 2020, accepted 7 September 2020.

*Corresponding author (tongsookim@inha.ac.kr)

(c) 2020, Korean Society for Parasitology and Tropical Medicine

This is an Open Access article distributed under the terms of the Creative Commons Attribution Non-Commercial License (https://creativecommons.org/licenses/by-nc/4.0) which permits unrestricted non-commercial use, distribution, and reproduction in any medium, provided the original work is properly cited.
}

Administration (KMA), the temperature of the Korean Peninsula has risen geographically with the increase of $\mathrm{CO}_{2}$ concentrations across the globe and in Korea $[7,8]$. The Intergovernemntal Panel on Climate Change (IPCC) has predicted an average temperature rise globally of $1.5-5.8^{\circ} \mathrm{C}$ during the $21 \mathrm{st}$ century [9].

Global warming is affecting the survival and density of poikilothermal animals, including insects. Korea has the opportunity to implement systematic countermeasures against the flow of mosquito-borne infectious diseases into the country. Almost 350 million estimated cases of mosquito-borne diseases were recognized globally in 2017 [10]. In this sense, vector control has become a pivotal portion of the worldwide strategy to manage mosquito-associated diseases, especially Japanese encephalitis, West Nile encephalitis, malaria, and dengue fever.

The genus Flavivirus (family Flaviviridae) comprises a diverse 
group of viruses and contains a variety of important human pathogens causing hemorrhagic fever and encephalitis [11]. A number of flaviviruses are considered major human pathogens. Mosquito-borne viruses can broadly be grouped as those transmitted by Culex spp. mosquitoes and associated generally with neurotropic viruses, and those transmitted by Aedes spp. mosquitoes and associated more closely with viscerotropic or hemorrhagic disease in humans. In addition, a number of insectspecific flaviviruses have been identified as non-vectored flaviviruses and a number of insect-specific flaviviruses have been identified in mosquitoes, such as Chaoyang virus, Culex flavivirus, and Aedes flavivirus [12], and several viruses have been identified as non-vectored flaviviruses. Regardless, the flaviviruses remain elusive about the flaviviruses. To heighten awareness of the risks of flavivirus-caused diseases and the potential for continued spread of these viruses, it is critical to monitor populations of the vectors.

The global environment is changing rapidly as a result of human activities, including population growth, urbanization, economic growth, natural resource use, and energy production, among others. Indeed, climate change has accelerated profound changes in ecosystems that influence human life. Thus, relying on monitoring to enable timely warnings can help protect the health of the public. The aims of this study are: 1) to report on species composition and abundance of vector mosquitoes and the pathogens they are carrying in urban areas and in habitats for migratory birds of Incheon and a rural area in Hwaseong during 2019; 2) to monitor and reduce the potential for the autochthonous transmission of imported mosquitoborne viruses. The approach in this study could provide the basis for epidemiological studies and risk assessment of vectorborne pathogens that enter Korea because of climate change.

\section{MATERIALS AND METHODS}

\section{Collection sites}

From March to November 2019, observational, descriptive, and prospective monitoring was performed to identify any circulating flaviviruses in different mosquito species in some areas in the middle of Korea Peninsula. Vector mosquitoes were collected in 7 regions: downtown Incheon (Bupyeong dong, Yeonhui dong, and Shinheung dong) as typical urban areas, habitats of migratory birds of Incheon (3 sites in Gyeongseo dong), and the Hwaseong-si area (a cowshed in Hogok-ri, Gyeonggi-do) as a rural area. Supplementary Table S1 presents the geographic coordinates recorded using a handheld GPS tracker where traps were set for the collection of mosquitoes. Incheon has a humid subtropical/continental climate [13] and the Köppen-Geiger climate classification for Incheon is Dwa (Continental, Dry summer, and Hot summer). Hwaseong-si is a city in Gyeonggi-do and the climate classification of this area based on the Köppen-Geiger method is also Dwa.

\section{Collection of mosquitoes}

Four traps were set up at each of the study sites. Adult mosquitoes were continuously collected for $24 \mathrm{hr}$ at 2-week intervals from March to November 2019 using black light traps and BG Sentinel ${ }^{\mathrm{TM}}$ traps. Mosquitoes were transferred from the traps into a Styroform cooler on wet ice and transported to the laboratory of Department of Parasitology and Tropical Medicine \& Global Resource Bank of Parasitic Protozoa Pathogens, Inha University, School of Medicine. Female mosquitoes were identified and confirmed morphologically using taxonomic keys $[14,15]$ and were compared with standard specimens in the collection of Inha University, School of Medicine and the Korea Centers for Disease Control and Prevention (KCDC). The abbreviations for the mosquito genera and subgenera follow the standardization proposed by Reinert [16]. The collected mosquitoes were pooled (1-30/pool) by species, collection site, and time of survey and quickly transferred to microcentrifuge tubes at $4^{\circ} \mathrm{C}$, where they were assayed for flaviviruses including Japanese encephalitis virus, West Nile virus, yellow fever virus, Zika virus and dengue fever virus. In total, 989 mosquito pools were analyzed for flavivirus identification.

RNA extraction and quantitative real-time (qRT)-PCR analysis of mosquito pools for flavivirus detection

To improve extraction and achieve high efficiency, and to reduce variability in the total RNA yields, bead beaters with QIAamp $^{\text {TM }}$ viral RNA mini kit were used in accordance with the manufacturer's protocols (Qiagen 52904, Qiagen $\mathrm{GmbH}$, Hilden, Germany). After RNA extraction from the homogenized mosquito samples, the extracted total RNA was resuspended in RNase-free water containing RNAsin ${ }^{\text {TM }}$ Plus RNase inhibitor (Promega Corporation, Madison, Wisconsin, USA) and then stored at $-70^{\circ} \mathrm{C}$ until use. qRT-PCR assays were conducted using a Verso SYBR Green 1-step qRT-PCR kit (Thermo AB4104, Thermo-Fisher Scientific, Waltham, Massachusetts, USA) in accordance with the manufacturer's protocols for the detection of pathogens in mosquitoes [17]. The specific prim- 
ers for nonstructural protein 5 (NS 5) used were as follows: PFlav-fAAR (sense) 5'-TACAACATGATG-GGAAAGAGAGAGAARAA-3', PFav-rKR (anti-sense) 5'-GTGTCCCAKCCRGCTGTGTCATC-3'. qRT-PCR was performed using $1.0 \mu$ PrimeScrip $^{\text {TM }}$ 1-step enzyme mix, $12.5 \mu \mathrm{l} 2 \times 1$ step SYBR RT-PCR buffer, each with $1 \mu \mathrm{M}$ primer, and $1 \mathrm{pg}$ to $100 \mathrm{ng}$ total RNA in a 25 $\mu$ total reaction volume. qRTR-PCR conditions for each reaction were $30 \mathrm{~min}$ at $50^{\circ} \mathrm{C}$, followed by $15 \mathrm{~min}$ at $95^{\circ} \mathrm{C}$, then 15 sec at $95^{\circ} \mathrm{C}, 20 \mathrm{sec}$ at $58^{\circ} \mathrm{C}$ and $30 \mathrm{sec}$ at $72^{\circ} \mathrm{C}$ for 45 cycles, and finally annealed for $1 \mathrm{~min}$ at $60^{\circ} \mathrm{C}$. Samples that generated a detectable fluorescence signal when assayed were determined to be flavivirus positive by monitoring the increase in fluorescence of a dye labeled oligonucleotide probe $[17,18]$. Using a Verso SYBR Green 1-step qRT-PCR kit with the positive samples, the cDNAs were re-assayed using the same primer set at the PCR condition of $2 \mathrm{~min}$ at $94^{\circ} \mathrm{C}$, then $30 \mathrm{sec}$ at $94^{\circ} \mathrm{C}, 20$ sec at $58^{\circ} \mathrm{C}$ and $30 \mathrm{sec}$ at $72^{\circ} \mathrm{C}$ for 30 cycles, and finally annealed for $5 \mathrm{~min}$ at $72^{\circ} \mathrm{C}$. The PCR products (202 bp in size) were then sent to Macrogen company (Macrogen, Seoul, Korea), where the obtained DNA sequences were edited and assembled for flavivirus classification.

\section{RESULTS}

\section{Mosquitoes collected}

In total, 79,209 (2,683 pools) female mosquitoes comprising 15 species (Aedes albopictus, Ae. vexans nipponii, Ae. vexans vexans, Armigeres subalbatus, Coquillettidia ochracea, Culex inatomii, $C x$. bitaeniorhynchus, $C x$. orientalis, $C x$. pipiens complex, $C x$. tritaeniorhynchus, Cx. vegans, Mansonia uniformis, Ochlerotatus dorsalis, Och. koreicus, and Anopheles spp.) were collected from March to November 2019 (Table 1) at the 7 locations in the downtown and habitats of migratory bird in Incheon and one location in a cowshed in Hwaseong-si areas. Ae. vexans nipponii was the most frequently collected mosquitoes (56.5\%), followed by Och. dorsalis (23.6\%), Anopheles spp. (10.9\%), and $C x$. pipiens complex (5.9\%). The remaining 11 species comprised $<1.00 \%$ of the total number of mosquitoes collected. The mosquitoes had periods of high prevalence (Fig. 1; Table 2). Ae. vexans nipponii populations increased from late May until late August peaking in late June; Och. dorsalis populations increased from late June to late September peaking in late June. Ae. vexans nipponii and Och. dorsalis showed clear 3 peaks in abundance through the year, with highest numbers collected during the late June ( $42.9 \%$ and $40.6 \%$, respectively). Ae. vex- ans nipponii showed other peaks at late May and early August, while Och. dorsalis showed them in early August and late September. Prevalence patterns for urban and rural regions were as expected, with more mosquitoes collected in the rural region of Hwaseong (89.8\%) and in the habitat regions of Incheon (6.9\%), a finding similar to many studies $[19,20]$ (Table 1). In rural regions of Hwaseong, Ae. vexans nipponii maintained the highest population (62.9\%), followed by Och. dorsalis (23.9\%) and Anopheles spp. (12.0\%). In another rural region of Incheon (habitat of migratory birds), Cx. pipiens complex maintained the highest population (31.4\%), followed by Och. dorsalis (30.5\%), and Ae. vexans vexans (27.5\%). However, $C x$. pipiens complex was the predominant species in the urban region $(84.7 \%)$ and the other species made up $<5 \%$ of the total mosquitoes collected during the collection period (Table 1). The other mosquito species made up $<1 \%$ of the total mosquitoes collected during the monitoring period and the sizes of the populations of these species were too small to be considered pivotal vectors in this monitoring study.

\section{Flaviviruses in mosquito vectors}

After qRT-PCR using a Verso SYBR Green 1-step qRT-PCR kit, the amplicons of PCR using the first amplified cDNA from the positive pooled mosquito samples were sequenced. The sequences were edited and assembled to obtain small DNA fragments of $202 \mathrm{bp}$ in size. From the analysis of the derived nucleotide sequences for matching genotypes using NCBIBLAST service, 3 pools of $C x$. pipiens pallens (from 989 total pools) tested positive for Culex flavivirus (Table 3) [21]. The maximum likelihood estimations (the estimated number of virus-positive mosquitoes/1,000 mosquitoes) for $C x$. pipiens pallens was 25 (Table 3). These mosquitoes were collected from the habitat for migratory birds (Gyeongseo-dong (\#2 site)) in Incheon during the first and second weeks of April and the first week of May 2019. Cx. pipiens pallens is a nuisance mosquito that exists widely throughout Korea and was the most frequently captured mosquito in the habitat of migratory birds (Table 1). Other types of flaviviruses were not identified using Verso SYBR Green 1-step qRT-PCR assays.

\section{DISCUSSION}

The climate in Korea has changed gradually from temperate to subtropical, making the Korean Peninsula environmentally preferable for the proliferation of vector mosquitoes in the 


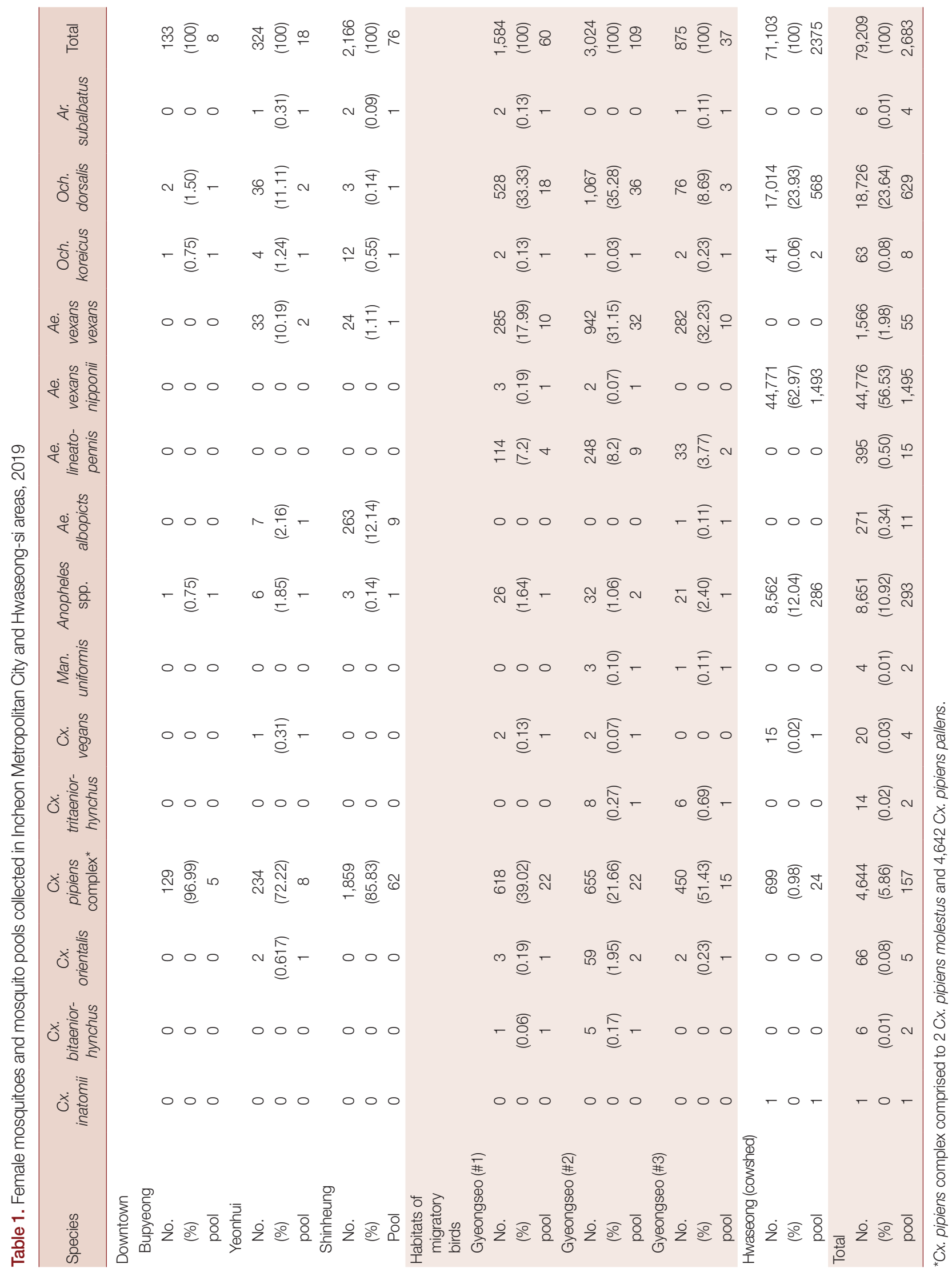




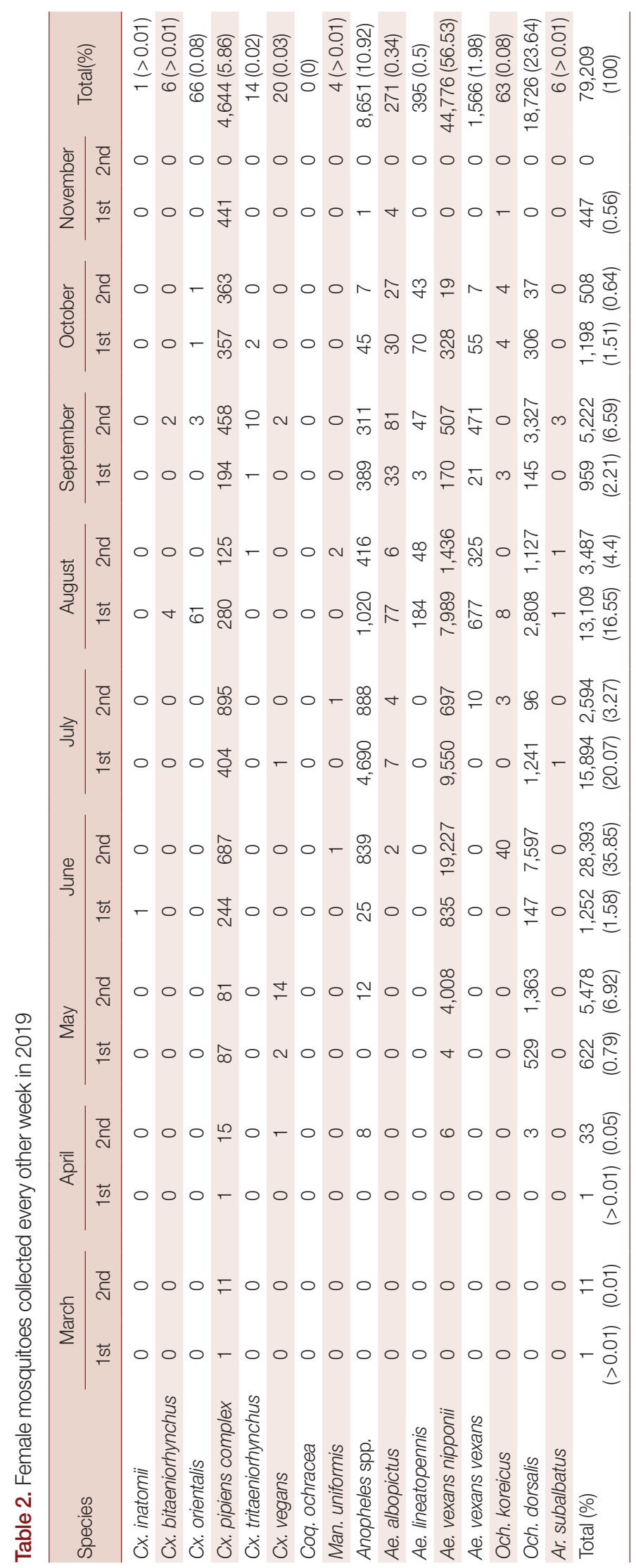

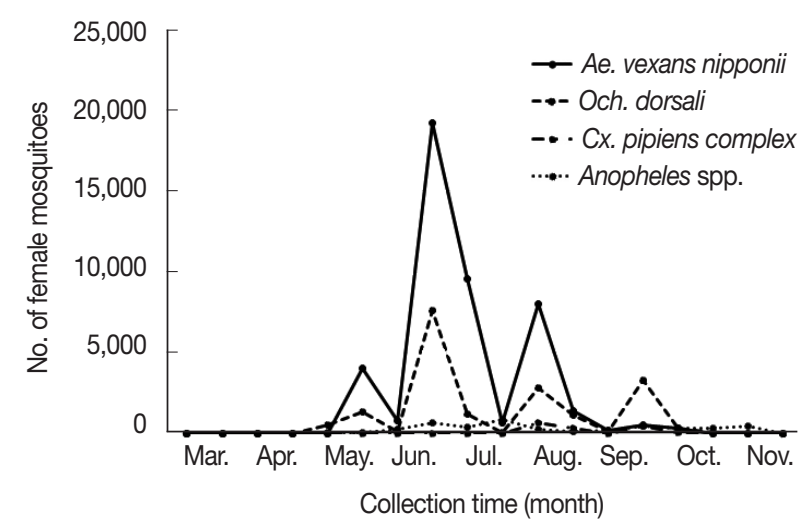

Fig. 1. Populations of each mosquito species including Aedes vexans nipponii, Ochlerotatus dorsalis, Anopheles spp., and Culex pipiens complex collected from March to November 2019.

Table 3. Incidence of flavivirus in culicine mosquitoes detected using qRT-PCR and determined using maximum likelihood estimation (MLE) in 2019

\begin{tabular}{lrrrr}
\hline Mosquitoes & $\begin{array}{c}\text { No. of } \\
\text { mosquitoes } \\
\text { collected }\end{array}$ & $\begin{array}{r}\text { No. } \\
\text { of } \\
\text { pools }\end{array}$ & $\begin{array}{c}\text { No. of } \\
\text { flavivirus } \\
\text { positive } \\
\text { pools (\%) }\end{array}$ & $\begin{array}{c}\text { Virus } \\
\text { identification } \\
(\text { MLE) }\end{array}$ \\
\hline Ae. albopictus & 271 & 20 & 0 & \\
Ae. lineatopennis & 395 & 21 & 0 & \\
Ae. vexans nipponii & 44,697 & 320 & 0 & \\
Ae. vexans vexans & 1,566 & 70 & 0 & \\
Ar. subalbatus & 6 & 5 & 0 & \\
Cx. bitaeniorhynchus & 6 & 3 & 0 & \\
Cx. inatomii & 1 & 1 & 0 & \\
Cx. orientalis & 66 & 6 & 0 & \\
Cx. pipiens molestus & 2 & 1 & 0 & \\
Cx. pipiens pallens & 4,642 & 211 & $3(1.42)$ & Culex \\
flaviviruses (25) & & & & \\
Cx. tritaeniorhynchus & 16 & 6 & 0 & \\
Cx. vagans & 17 & 4 & 0 \\
Man. uniformis & 5 & 4 & 0 & \\
Och. dorsalis & 18,705 & 304 & 0 \\
Och. koreicus & 63 & 13 & 0 \\
Total & 70,558 & 989 & $3(0.30)$ \\
\hline
\end{tabular}

${ }^{a} M L E$, estimated number of flaviviral RNA positive mosquitoes per 1,000 .

near future [22]. Climate variables such as precipitation and temperature, which have changed significantly as a result of global warming, are major driving forces of vector-borne diseases and altered the exposure pathways. The determinants could influence the fate and transport of pathogens, as well as their stability, reproduction rates, and variability in the environment, especially mosquitoes for serious vector-borne diseases, such as dengue fever, Japanese encephalitis, Zika fever, Chikungunya fever, yellow fever, and West Nile fever-the majority of 


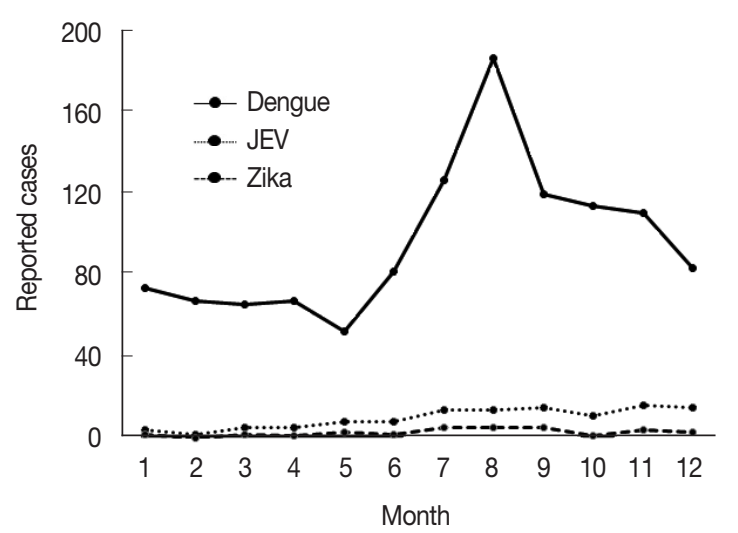

Fig. 2. Monthly accumulated cases of indigenous mosquitoborne diseases including dengue fever, Japanese encephalitis, and Zika fever [23] in Korea during 2015-2019.

which are zoonoses that infect a range of vertebrate hosts via mosquitoes and can cause serious public health issues. In Korea, these infectious diseases are classified as group III infectious diseases according to the Korean Act on the Prevention and Control of Infectious Diseases. Currently, the major indigenous mosquito-borne infectious diseases in Korea are vivax malaria and dengue virus infection and the minor ones are Japanese encephalitis and Zika fever (Fig. 2). During a 5-year period (2015-2019), 1,171 clinical cases of dengue fever were reported in Korea [23]. Although approximately 1,600 cases of Japanese encephalitis were reported annually until 1970s, total cases decreased dramatically to 129 from 2015 to 2019 because of the introduction of an effective vaccine and a mandatory vaccination program [24]. In case of Zika virus infection in Korea, 33 total clinical cases were reported during 2016-2019 [23]. Although no cases of other flaviviral diseases, such as Chikungunya fever, yellow fever, and West Nile fever, have been reported as indigenous to Korea to date, it is highly likely, based on the existence of the vector mosquitoes in Korea that the context might change if the mosquito-borne diseases are introduced from the outside of country.

Kim et al. [25] studied the population densities of culicine mosquitoes and reported Ae. vexans nipponii maintained the highest population (50.7\%), followed by Cx. tritaeniorhynchus (36.6\%), Cx. pipiens complex (7.5\%), Och. dorsalis (2.1\%), and $C x$. bitaeniorhynchus (1.3\%). The present study found that Ae. vexans nipponii was the most frequently collected species, followed by Och. dorsalis, Anopheles spp., and Cx. pipiens complex. Obvious differences exist between Incheon (an urban area) and Hwaseong (a rural area) in the species collected. In rural regions of Hwaseong, Ae. vexans nipponii maintained the high- est population, followed by Och. dorsalis and Anopheles spp. In another rural region of Incheon (habitat of migratory birds), $C x$. pipiens complex maintained the highest population, followed by Och. dorsalis, and Ae. vexans vexans. In urban area, $C x$. pipiens complex was the predominant species. From the surveillance of the vector mosquitoes carrying flaviviruses during April to November 2015 in Incheon and Hwaseong [26], the Cx. pipiens complex was the most collected species (81.9\%) in downtown Incheon followed by Ae. vexans nipponii (11.8\%) and Och. koreicus (2.9\%), whereas Ae. vexans nipponii was the most collected species in Hwaseong (58.9\%) followed by $C x$. pipiens complex (15.3\%), Och. koreicus (13.9\%), and Och. dorsalis (11.1\%). The other species made up less than $2 \%$ of the total mosquitoes collected during the collection period [26]. From the surveillance data collected during 2016-2018 in Incheon and Hwaseong [19], Ae. vexans nipponii comprised $49.1 \%$ of the population and $C x$. pipiens, Och. dorsalis, Och. koreicus, and $C x$. tritaeniorhynchus comprised 31.8\%, 13.6\%, 1.7\%, and 1.5\% of the population, respectively. Although $C x$. tritaeniorhynchus is the major mosquito vector throughout Asia, including Korea, and $C x$. bitaeniorhynchus has been implicated recently as a vector of Japanese encephalitis in Korea, the populations of these 2 species made up less than $0.02 \%$ of the total number of mosquitoes collected and were not considered important vectors in our study sites.

Previous surveillances during April to November 2015 and during 2016 to 2018 found 3 Japanese encephalitis genotype V viruses from $C x$. pipiens complex pools and of one Chaoyang virus from Ae. vexans nipponii pools, respectively $[19,26]$. In the present study, we found 3 Culex flavivirus positive cases from the $C x$. pipiens pallens pooling samples at the habitat for migratory birds in Incheon. However, other genotype- and insect-specific flaviviruses and pathogenic flaviviruses were not found in this study. An insect-specific flavivirus isolated in Korea has been identified recently as $98.9 \%$ homologous to the first-reported Chaoyang virus from Liaoning Province, China, grouped genetically within the mosquito-borne flavivirus cluster $[27,28]$. The genus Flavivirus includes many pivotal human pathogens causing hemorrhagic fever and encephalitis, such as dengue fever, Japanese encephalitis, Zika fever, Chikungunya fever, yellow fever, and West Nile fever. The Chaoyang virus, which is limited to insects alone, is referred to as an 'insect-specific' virus that naturally infects mosquitoes and replicates in mosquito cells in vitro, but does not appear to replicate in vertebrate cells or to infect humans or other vertebrate $[29,30]$. Culex flavivirus 
has been isolated and characterized from Culex mosquitoes in Japan [21], Guatemala, Mexico, and the USA [31]. The insectspecific flaviviruses are speculated to represent the genetic primordial form of the genus [21]. Culex flaviviruses are distributed widely in the natural environment and can infect various mosquito species [31]. Culex flaviviruses have been detected in $C x$. pipiens, $C x$. quinquefasciatus, $C x$. restuans, $C x$. tritaeniorhynchus, and Anopheles sinensis in Japan, Indonesia, the USA, Uganda, China, Mexico, and Brazil [32]. In the present monitoring, the 3 Culex flavivirus positive cases from the $\mathrm{Cx}$. pipiens pallens samples were detected during the first and second weeks of April and the first week of May 2019. We continued to sample Culex mosquitoes to November 2019 but did not detect any more flavivirus-positive mosquito pools. In fact, Culex mosquitoes are seasonal in this study and the highest peak of appearance of these mosquitoes was in late July, followed by late June (Table 2). However, the total number of individuals collected from the $C x$. pipiens complex is relatively small compared to other species. We recognize that an important limitation in this study is lack of data for more than one year with which to test the consistency of seasonal trends.

Biological control measures involve the use of natural predators or pathogens to reduce mosquito abundance or vector competence. From recent studies with Wolbachia, a bacterial that infects arthropod species, maternally inherited bacterial endosymbionts found in a variety of arthropod species have been used to reduce insect populations by way of cytoplasmic incompatibility [33]. Certain Wolbachia strains have the potential to reduce the vector competence of mosquitoes by rendering them refractory to certain human pathogens [34]. If a bacterial symbiont can alter the vector competence of a mosquito for arboviruses, then it seems likely that certain viral symbionts may have similar effect [35]. Although this phenomenon is not yet fully characterized, it may be feasible to create a population of mosquitoes in which the individuals are unable to transmit certain human pathogenic arboviruses [30]. This study might be leveraged as part of future mosquito surveillance for a better comprehension of insect-specific flaviviruses circulating in mosquitoes in Korea. Furthermore, research to elucidate any effect of the interaction between insect-specific flavivirus and human pathogenic flaviviruses is of critical importance.

In conclusion, we examined the status of flaviviral diseases transmitted by mosquitoes and investigated the abundance of mosquito populations in downtown and in habitats for migra- tory birds of Incheon and a cowshed of Hwaseong, Korea from March to November 2019. Climate change is a driving forces in altering the distribution, reproduction, and activity of mosquito populations and influencing the prevalence of mosquito-borne pathogens causing public health issues. Intensified monitoring and long-term surveillance of both the vectors and viruses they transmit are significant to global public health.

\section{ACKNOWLEDGMENT}

This work was supported by the Inha University Research Fund and the Korea Centers for Disease Control and Prevention (Vector Surveillance in First Metropolitan City) in the Republic of Korea.

\section{CONFLICT OF INTEREST}

The authors declare that they have no conflicts of interest.

\section{REFERENCES}

1. Kovats S, Haines A. The potential healwth impacts of climate change: an overview. Med War 1995; 11: 168-178.

2. Githeko AK, Linsay SW, Confalonieri UE, Patz JA. Climate change and vector-borne diseases: a regional analysis. Bull World Health Organ 2000; 78: 1136-1147.

3. Ogden NH. Climate change and vector-borne diseases of public health significance. FEMS Microbiol Lett 2017; 364: fnx186.

4. McMicheal AJ, Woodruff RE, Hales S. Climate change and human health: present and future risks. Lancet 2006; 367: 859-869.

5. Masson-Delmotte V, Zhai P, Portner HO, Roberts D, Skea J, Shukla PR, Pirani A, Moufouma-Okia W, Pean C, Pidcock R, Connors S, Matthews JBR, Chen Y, Zhou X, Gomis MI, Lonnoy E, Maycock T, Tignor M, Waterfield T. 2018: Framing and Context. In Global Warming of $1.5^{\circ} \mathrm{C}$. An IPCC Special Report on the impacts of global warming of $1.5^{\circ} \mathrm{C}$ above pre-industrial levels and related global greenhouse gas emission pathways, in the context of strengthening the global response to the threat of climate change, sustainable development, and efforts to eradicate poverty. Geneva, Switzerland. Intergovernmental Panel on Climate Change. 2018.

6. Min SK, Zhang X, Zwiers F, Shiogama H, Tung YS, Wehner M. Multimodel detection and attribution of extreme temperature changes. J Climate 2013; 26: 7430-7451.

7. Chung YS, Yoon MB, Kim HS. On climate variations and changes observed in South Korea. Climate Change 2004; 66: 151-161.

8. Korea Meteorological Administration. 2019 Abnormal Weather Report [Internet]; [cited 2020 Feb 20]. Available from: http:// www.climate.go.kr/home/bbs/view.php?code=93\&bname=abn 
ormal\&vcode $=6385 \&$ cpage $=1 \&$ vNum=Notice $\&$ skind $=\&$ sword $=$ \&category $1=$ \&ategory2.

9. Field CB, Barros V, Stocker TF, Qin D, Dokken DJ, Ebi KL, Mastrandrea MD, Mach KJ, Plattner G-K, Allen SK, Tignor M, Midgley PM. Managing the Risks of Extreme Events and Disasters to Advance Climate Change Adaptation: Special Report of Working Groups I and II of the Intergovernmental Panel on Climate Change. Cambridge, UK, and New York, USA. Cambridge University Press. 2012, pp 1-582.

10. World Health Organization, UNICEF. Global Vector Control Response 2017-2030. Geneva, Switzerland. World Health Organization. 2017.

11. Holbrook MR. Historical perspectives on flavivirus research. Viruses 2017; 9: 97.

12. Blitvich BJ, Firth AE. Insect-specific flaviviruses: A systematic review of their discovery, host range, mode of transmission, superinfection exclusion potential and genomic organization. Viruses 2015; 7: 1927-1959.

13. Kottek M, Grieser J, Beck C, Rudolf B, Rubel F. World map of the Köppen-Geiger climate classification updated. Meteorol Z. 2006; 15: 259-263.

14. Tanaka K, Mizusawa K, Saugsad ES. A revision of the adult and marvel mosquitoes of Japan (including the Ryuku Archipelago and the Ogasawara Islands) and Korea (Diptera: Culicidae). Contrib Am Entomol Instit 1979; 16: 1-987.

15. Ree HI. Taxonomic review and revised keys of the Korean mosquitoes (Diptera: Culicidae). Entomol Res 2003; 33: 39-52.

16. Reibert JE. Revised list of abbreviations for genera and subgenera of Culicidae (Diptera) and notes on genetic and subgenetic changes. J Am Mosq Control Assoc 2001; 17: 51-55.

17. Yang CF, Chen CF, Su CL, Teng HJ, Lu LC, Lin C, Wang CY, Shu PY, Huang JH, Wu HS. Screening of mosquitoes using SYBR Green 1-based real-time RT-PCR with group-specific primers for detection of flaviviruses and alphaviruses in Taiwan. J Virol Methods 2010; 168: 147-151.

18. Chao DY, Davis BS, Chang GJ. Development of mulplex realtime reverse transcriptase PCR assays for detecting eight medically important flaviviruses in mosquitoes. J Clin Microbiol 2007; 45: 584-589.

19. Jegal S, Jun H, Kim-Jeon MD, Park SH, Ahn SK, Lee J, Gong YW, Joo K, Kwon MJ, Roh JY, Lee WG, Lee W, Bahk YY, Kim TS. Three-year surveillance of culicine mosquitoes (Diptera: Culicidae) for flavivirus infections in Incheon Metropolitan City and Hwaseong-si of Gyeonggi-do Province Republic of Korea. Acta Trop 2020; 202: 105258.

20. Honnen AC, Monaghan MT. City-dwellers and country folks: lack of population differentiation along an urban-rural gradient in the mosquito Culex pipiens (Diptera: Culicidae). J Insect Sci 2017; 17: 107.

21. Hoshino K, Isawa H, Tsuda Y, Yano K, Sasaki T, Yuda M, Taksaki T, Kobayashi M, Sawabe K. Genetic characterization of a new insect flavivirus isolated from Culex pipiens mosquito in Japan. Virology 2007; 359: 405-414.

22. Yeom JS. Current status and outlook of mosquito-borne diseases in Korea. J Korean Med Assoc 2017; 60: 468-474 (In Korean).

23. Korean Centers for Diseases Control and Prevention. Infectious Diseases Surveillance System [Internet]; Available from: http:// is.cdc.go.kr/.

24. Bae W, Kim JH, Kim J, Lee J, Hwang ES. Changes of epidemiological characteristics of Japanese encephalitis viral infection and birds as a potential viral transmitter in Korea. J. Korean Med Sci 2018; 33: e70.

25. Kim HC, Chong ST, Pike JG, O'Guinn MI, Pacha LA, Lee HC, Klein TA. Seasonal prevalence of mosquitoes collected from light traps in the Republic of Korea. Entomol Res 2002; 34: 177186.

26. Bahk YY, Jun H, Jegal S, Kim-Jeon MD, Rho JY, Lee WG, Park SH, Ahn SK, Lee J, Gong YW, Kwon MJ, Kim TS. Flaviviral disease mosquito vector surveillance in Incheon Metropolitan City and the Hwaseong area, Gyeonggi-do, Republic of Korea. Entomol Res 2020; 50: 3-13.

27. Lee JS, Grubaugh ND, Kondig JP, Turell MJ, Kim HC, Klein TA, O'Guinn ML. Isolation and genomic characterization of Chaoyang virus strain ROK144 from Aedes vexans nipponii from the Republic of Korea. Virology 2013; 435: 220-224.

28. Takhampunya R, Kim HC, Tippayachai B, Lee DK, Lee WJ, Chong ST, Kim MS, Lee JS, Klein TA. Distribution and mosquito hosts of Chaoyang virus a newly reported flavivirus from the Republic of Korea, 2008-2011. J Med Entomol 2014; 51: 464474.

29. Kuno G. Host range specificity of flaviviruses: correlation with in vitro replication. J Med Entomol 2007; 44: 93-101.

30. Bolling BG, Weaver SC, Tesh RB, Vasilakis N. Insect-specific virus discovery: Significance for the arbovirus community. Viruses 2015; 7: 4911-4928.

31. Cook S, Moureau G, Kitchen A, Gould EA, de Lamballerie X, Holmes EC, Harbach RE. Molecular evolution of the insect-specific flaviviruses. J Gen Virol 2012; 93: 223-234.

32. Fang Y, Zhang Y, Zhou ZB, Shi WQ, Xia S, Li YY, Wu JT, Liu Q, Lin GY. Co-circulation of Aedes flavivirus, Culex flavivirus, and Quang Binh virus in Shanghai China. Infect Dis Poverty 2018; 7: 75 .

33. Laven H. Eradication of Culex pipiens fatigans through cytoplasmic incompatibility. Nature 1967; 216: 383-384.

34. Kambris Z, Blagborough AM, Pinto SB, Blagrove MS, Godfray HC, Sinden RE, Sinkins SP. Wolbachia stimulates immune gene expression and inhibits plasmodium development in Anopheles gambiae. PLoS Pathog 2010; 6: e1001143.

35. Vasilakis N, Forrester NL, Palacios G, Nasar F, Savji N, Rossi SL, Guzman H, Wood TG, Popov V, Gorchakov R, González AV, Haddow AD, Watts DM, da Rosa AP, Weaver SC, Lipkin WI, Tesh RB. Negavirus: A proposed new taxon of insect-specific viruses with wide geographic distribution. J Virol 2013; 87: 2475-2488. 